Abbreviated Key Title: Sch J Med Case Rep

ISSN 2347-9507 (Print) | ISSN 2347-6559 (Online)

Journal homepage: http://saspjournals.com/sjmcr

\title{
Cervicothoracic Necrosis Fascia Following an Insect Bite
}

Mahiou Noureddine ${ }^{1 *}$, Laasikri $\mathrm{Omar}^{2}$, Maouni $\mathrm{Safae}^{2}$, Nitassi Sophia ${ }^{1}$, Razika Bencheikh ${ }^{1}$, Oujilal Abelilah ${ }^{1}$, Anas Benbouzid $^{1}$, Essakalli Leilla ${ }^{1}$

${ }^{1}$ Department of Otolaryngology, Head and Neck Surgery, Ibn Sina University Hospital, Mohammed V University, Rabat, Morocco

${ }^{2}$ Department of Dermatology, Ibn Sina University Hospital, Mohammed V University, Rabat, Morocco

DOI: $10.36347 /$ simcr.2020.v08i07.013

| Received: 19.10.2019 | Accepted: 26.10.2019| Published: 26.07.2020

*Corresponding author: Mahiou Noureddine

Abstract

Case Report

Necrotizing bacterial dermohypodermitis with necrotizing fasciitis (DHBN-FN) is a infection of the hypodermis, the muscular fascia and secondarily the dermis. The infection sometimes spreads in a fulminating manner along the fascia. It constitutes a medical-surgical emergency. It is a rare and serious infection. The mortality remains high reaching $19 \%$ to $41 \%$, despite an improvement in surgical techniques and resuscitation. We reports the case of old men of 65 years with diabetes as co-morbidity and discusses the clinical, therapeutic and evolutionary aspects through the literature.

Keywords: Necrotizing Fasciitis, infection; insect bite.

Copyright @ 2020: This is an open-access article distributed under the terms of the Creative Commons Attribution license which permits unrestricted use, distribution, and reproduction in any medium for non-commercial use (NonCommercial, or CC-BY-NC) provided the original author and source are credited.

\section{INTRODUCTION}

Necrotizing bacterial dermohypodermitis with necrotizing fasciitis (DHBN-FN) is a necrotizing infection of the hypodermis, the muscular fascia and secondarily the dermis. The infection sometimes spreads in a fulminating manner along the fascia. It constitutes a medical-surgical emergency. It is a rare and serious infection. The mortality remains high, despite an improvement in surgical techniques and resuscitation.

\section{Case STudy}

65-year-old men admitted to the emergency room for anterior cervico-thoracic pain with edema. The onset of the disease was 30 days after an insect sting in the cervical region. She undertook a self-medication treatment that did not improve. The pain evolved becoming more intense, insomniante, pulsatile, permanent and irradiating towards the anterior cervical and thoracic regions, the right breast. The pain was accompanied by fever at $39^{\circ} \mathrm{C}$, vomiting, hypersialorrhea, anorexia and slimming with weight loss of $8 \mathrm{~kg}$. On examination, there was a putrid odor of exudates, dehydration folds, and cyanic spots which were poorly limited in geography. An induration of the edema extending from the right neck to the anterior cervicothoracic region with Necrotic ulceration at insect bite point. tomodensitometry confirme the presence of cervico-mediastinal cellulitis (Figure-1). A surgical exploration included a hypodermic melt with a greenish creamy appearance, no pus frank, a large area of skin detachment, necrotizing fasciitis, rare bleeding, Myositis. Then the patient was hospitalized in intensive care unit with set up of adapted medical treatment and change of dressing qoutidien but unfortunately the patient died 4 days after its admission.

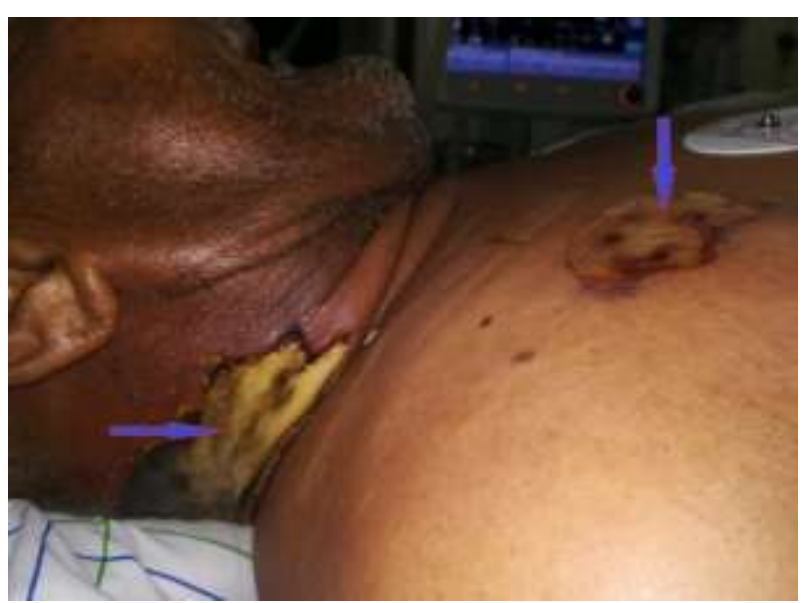

Fig-1: An induration of the edema extending from the right neck to the anterior cervicothoracic region with Necrotic ulceration at insect bite point (red arrows)

\section{DISCUSSION}

Despite the development of antibiotic therapy, suppurations peripharyngeal defects can be observed. They are dominated in our experience with the periamygdalian phlegmon [3]. 
Fasciitis necrotizing is not an exceptional complication, however. It is said to be linked to certain favourable factors, in particular the states immunosuppression induced by diabetes, HIV infection, diabetes malnutrition $[1,4,5]$.

These factors have not been identified in our 2 patients, in whom we can nevertheless accuse a precariousness linked to the low standard of living. The harmful role of NSAIDs, in addition to being used for self-medication, appears to be used again confirmed [1, $3,4]$.

Cervical necrotizing fasciitis would generally be of origin odontogenic, representing nearly $78 \%$ of cases in some cases series $[4,5]$; even if one of the patients had multiple caries, the oropharyngeal starting point seems more likely, being given the concomitant tonsil lesions [4-6].

The origin Pharyngeal fasciitis is not uncommon (from 16 to $44 \%$ of cases)[4, 7]; the initial existence of a periamygdalien abscess is not always shown [6].

The monobacterial isolation observed in our experience is less frequent than the classical microbial plurality and generally composed of group A streptococci and germs anaerobic [1, 4, 5]. Enterobacteriaceae and pseudomonas such as that highlighted in our patients are part of the germs other than streptococcus [1]. This infection of the tissues soft, described as "flesh-eating", is progressing rapidly, as shown by these 2 clinical cases.

The classic therapeutic attitude is the one that has been used in both cases, combining parenteral antibiotic therapy and surgery stripper $[1,2,4,5]$. Some teams have shown that a less invasive surgical treatment with catheter drainage type resulted in super imposable results [6-8].

Hyperbaric oxygen therapy would have indications, but its effectiveness is discussed $[1,8]$. The use of reconstructive surgery is conditioned by the squeal $[1,4]$.

The evolution has been unsatisfactory in our experience, because the thoracic locations which mediastinal extension $[1,2,4,5]$; the mortality rate, between 7 and $20 \%$.in the cervical forms, would reach $41 \%$ in the event of damage thoracic $[2,4,7]$.

\section{CONCLUSION}

Necrotizing cervical fasciitis is a severe and fulminant infection. Early diagnosis and treatment are necessary to reduce mortality. Aggressive and prompt surgery associated to antibiotic therapy is the most important factor in improving prognosis.

\section{REFERENCES}

1. Société de Pathologie Infectieuse de Langue Francaise. Société française de dermatologie. Conférence de consensus. Érysipèle et fasciite nécrosante: prise en charge. Med Mal Infect. 2000;30:241-245.

2. Sarna T, Sengupta T, Miloro M, Kolokythas A. Cervical necrotizing fasciitis with descending mediastinitis: literature review and case report. Journal of oral and maxillofacial surgery. 2012 Jun 1;70(6):1342-50.

3. Koffi-Aka V, Ehouo F, Azagoh KR, Adjoua RP, Kouassi B. Phlegmon péri-amygdalien à Abidjan. Lett Otorhinolaryngol Chir Cervicofac. 2007;311:26-8.

4. Mathieu D, Neviere R, Teillon C, Chagnon JL, Lebleu N, Wattel F. Cervical necrotizing fasciitis: clinical manifestations and management. Clinical infectious diseases. 1995 Jul 1;21(1):51-6.

5. Zilberstein B, Cleva RD, Testa RS, Sene U, Eshkenazy R, Gama-Rodrigues JJ. Cervical necrotizing fasciitis due to bacterial tonsillitis. Clinics. 2005 Apr;60(2):177-82.

6. Islam A, Oko M. Cervical necrotising fasciitis and descending mediastinitis secondary to unilateral tonsillitis: a case report. Journal of medical case reports. $2008 \mathrm{Dec} ; 2(1): 368$.

7. Sumi Y, Ogura H, Nakamori Y, Ukai I, Tasaki O, Kuwagata Y, Shimazu T, Tanaka H, Sugimoto H. Nonoperative catheter management for cervical necrotizing fasciitis with and without descending necrotizing mediastinitis. Archives of Otolaryngology-Head \& Neck Surgery. 2008 Jul 21;134(7):750-6.

8. Nakamori Y, Fujimi S, Ogura H, Kuwagata Y, Tanaka H, Shimazu T, Ueda T, Sugimoto H. Conventional open surgery versus percutaneous catheter drainage in the treatment of cervical necrotizing fasciitis and descending necrotizing mediastinitis. American Journal of Roentgenology. 2004 Jun;182(6):1443-9. 